\title{
Perioperative B-type natriuretic peptide levels predict outcome after bidirectional cavopulmonary anastomosis and total cavopulmonary connection
}

\author{
Jong-Hau Hsu, MD, a,d Peter E. Oishi, MD, ${ }^{a}$ Roberta L. Keller, MD, ${ }^{a}$ Omar Chikovani, MD, ${ }^{a}$ Tom R. Karl, MD, ${ }^{b}$ \\ Anthony Azakie, MD, ${ }^{b}$ Ian Adatia, MBChB, ${ }^{a}$ and Jeffrey R. Fineman, $\mathrm{MD}^{\mathrm{a}, \mathrm{c}}$
}

Objective: The objective of the study was to determine perioperative B-type natriuretic peptide levels in infants and children undergoing bidirectional cavopulmonary anastomosis or total cavopulmonary connection, and the predictive value of B-type natriuretic peptide levels for outcome.

Methods: Plasma B-type natriuretic peptide levels were measured before and 2, 12, and 24 hours after surgery in 36 consecutive patients undergoing bidirectional cavopulmonary anastomosis $(n=25)$ or total cavopulmonary connection $(n=11)$. B-type natriuretic peptide levels were evaluated as predictors of outcome.

Results: B-type natriuretic peptide levels increased after surgery, peaking at 12 hours in most patients. In the bidirectional cavopulmonary anastomosis group, patients with 12-hour B-type natriuretic peptide $\geq 500 \mathrm{pg} / \mathrm{mL}$ had a longer duration of mechanical ventilation $(165 \pm 149$ hours vs $20 \pm 9$ hours, $P=.004)$, longer intensive care unit stay ( $11 \pm 7$ days vs $4 \pm 2$ days, $P=.001)$, and longer hospital stay (20 days \pm 12 vs 9 days $\pm 5, P=.003$ ). A 12-hour B-type natriuretic peptide $\geq 500 \mathrm{pg} / \mathrm{mL}$ had a sensitivity of $80 \%$ and a specificity of $80 \%$ for predicting an unplanned surgical or transcatheter cardiac intervention, including transplantation

From the Department of Pediatrics, ${ }^{\mathrm{a}}$ Department of Surgery, ${ }^{b}$ and Cardiovascular Research Institute, ${ }^{\mathrm{c}}$ University of California, San Francisco, Calif; and Department of Pediatrics, Kaohsiung Medical University, ${ }^{\mathrm{d}}$ Kaohsiung Medical University Hospital, Kaohsiung, Taiwan.

This research was supported in part by grants K08 HL086513 (P.E.O.), K23 HL079922 (R.L.K.), HL61284 (J.R.F.), and UL RR024131-01 from the National Center for Research Resources, all from the National Institutes of Health, and from the Foundation Leducq (J.R.F.) and Biosite Diagnostic (J.R.F.). J.H.H. was supported in part by the Department of Pediatrics, Kaohsiung Medical University Hospital, Taiwan.

Received for publication Aug 30, 2007; revisions received Oct 5, 2007; accepted for publication Oct 31, 2007.

Address for reprints: Jeffrey R. Fineman, MD, Department of Pediatrics, UCSF Medical Center, 513 Parnassus Avenue, Box 0106, San Francisco, CA 94143 (E-mail: jeff.fineman@ucsf.edu).

J Thorac Cardiovasc Surg 2008;135:746-53 $0022-5223 / \$ 34.00$

Copyright $(\underset{2008}{ } 20 y$ The American Association for Thoracic Surgery

doi:10.1016/j.jtcvs.2007.10.040 $(P=.03)$. In the total cavopulmonary connection group, preoperative B-type natriuretic peptide levels were highest in patients with total cavopulmonary connection failure compared with patients with a good outcome $(88 \pm 46 \mathrm{pg} / \mathrm{mL}$ vs $15 \pm 6 \mathrm{pg} /$ $\mathrm{mL}, P=.03)$.

Conclusion: Postoperative B-type natriuretic peptide levels predict outcome after bidirectional cavopulmonary anastomosis, and preoperative levels are greater in patients with both early and late total cavopulmonary connection failure compared with patients with a good outcome.

$\mathrm{S}$ urgical palliation of univentricular cardiac defects usually requires a series of staged operations. Most often, the functionally single ventricle supplies blood in parallel to the systemic and pulmonary circulations after first-stage palliation. A bidirectional cavopulmonary anastomosis (BCPA) followed by a total cavopulmonary connection (TCPC) allows the transition of patients to a circulation in series, wherein the functionally single ventricle ejects blood to the systemic vasculature while passive venous return provides blood to the pulmonary vasculature. However, the absence of a dedicated subpulmonary ventricle requires the functionally single ventricle to supply the total kinetic energy for blood flow through both circulations, which renders patients sensitive to elevations in pulmonary vascular resistance (PVR), valvular dysfunction, or decreased ventricular performance. ${ }^{1-5}$ Although mortality after BCPA and TCPC is low with careful patient selection, the ability to predict adverse postoperative outcomes is inadequate, and there remains an unpredictable risk of early and late TCPC takedown because of poor adaptation to the Fontan circulation.

B-type natriuretic peptide (BNP) is a 32-amino acid polypeptide hormone secreted by the myocardium in response to various stimuli that has natriuretic, diuretic, and 


\section{Abbreviations and Acronyms \\ BCPA = bidirectional cavopulmonary anastomosis \\ $\mathrm{BNP}=\mathrm{B}$-type natriuretic peptide \\ $\mathrm{CPB}=$ cardiopulmonary bypass \\ ICU = intensive care unit \\ LCOS = low cardiac output syndrome \\ mPAP $=$ mean pulmonary artery pressure \\ PVR = pulmonary vascular resistance \\ $\mathrm{Qp} / \mathrm{Qs}$ = ratio of pulmonary blood flow over systemic blood flow \\ SVC = superior vena cava \\ SVEDP $=$ systemic ventricular end-diastolic pressure \\ TCPC = total cavopulmonary connection}

vasoactive properties. ${ }^{6,7}$ Recent studies found that BNP levels predicted postoperative morbidity and mortality after surgery for the repair or palliation of congenital cardiac defects. ${ }^{8-11}$ However, these studies also demonstrated marked variability in absolute BNP levels, perioperative changes in $\mathrm{BNP}$, and their specific predictive values, in part because of differences between the specific age groups and cardiac defects that were investigated. ${ }^{8-11}$ Thus, although the available data demonstrate clinical utility for BNP as a biomarker in subsets of patients after congenital cardiac surgery, they do not directly establish a use in patients after BCPA or TCPC.

We hypothesized that perioperative BNP levels would predict unexpected outcomes after BCPA and TCPC in patients otherwise deemed to be suitable operative candidates on the basis of standard preoperative hemodynamic assessments. Therefore, the objectives of this study were (1) to determine perioperative BNP levels in infants and children undergoing BCPA or TCPC, and (2) to investigate the potential predictive value of BNP levels for postoperative outcome.

\section{Materials and Methods}

We conducted a prospective cohort study in the pediatric cardiac intensive care unit (ICU) at the University of California, San Francisco Children's Hospital between July of 2005 and July of 2006. Eligible patients were children aged less than 17 years with congenital cardiac defects who were undergoing BCPA or TCPC.

The preoperative anesthesia management, intraoperative surgical strategy, and subsequent pediatric cardiac ICU management followed standard institutional practices. The surgical and medical teams involved in the management of the patients were blinded to the BNP values.

We obtained written informed consent from the patients' parents or guardians before enrollment in the study. The University of California, San Francisco review board approved the study.

\section{Data Collection}

Blood samples were obtained from an arterial catheter just after induction of anesthesia, and at 2, 12, and 24 hours after surgery. For patients who could not be separated from cardiopulmonary bypass (CPB), only the preoperative specimen was obtained. The samples were placed immediately on ice in chilled ethylenediamine tetraacetic acid-treated tubes and centrifuged at $3000 \mathrm{rpm}$ for 15 minutes at $4^{\circ} \mathrm{C}$. Separated plasma was stored at $-20^{\circ} \mathrm{C}$. Within 4 days, the plasma was thawed to room temperature and BNP levels were measured using a commercially available fluorescence immunoassay (Triage Meter Plus, Biosite Diagnostic, San Diego, Calif). The measurable range of BNP on this device is between 5 and $5000 \mathrm{pg} / \mathrm{mL}$. The estimated coefficient of variation for the assay is $9.2 \%$ to $11.4 \%$.

Perioperative clinical and biochemical data were collected prospectively at each sampling point and daily thereafter by an observer blinded to the BNP data. The clinical data collected included the following: patient demographics; preoperative hemodynamic data obtained at the time of cardiac catheterization, including the ratio of pulmonary blood to systemic blood flow (Qp/Qs), PVR, mean pulmonary artery pressure (mPAP), cardiac index, and systemic ventricular enddiastolic pressure (SVEDP); CPB duration; and postoperative hemodynamic and clinical outcomes, including inotrope dose, mean systemic arterial pressure, common atrial pressure, heart rate, ICU and hospital length of stay after operation, urine output, fluid balance 24 hours after surgery, and duration of mechanical ventilation. Perioperative biochemical data collected included hematocrit, arterial and venous blood gases, serum lactate, blood urea nitrogen, and creatinine.

\section{Outcome Measures}

The primary end point was the occurrence of an adverse outcome within 1 year of surgery, defined as death or the need for an unplanned surgical or transcatheter cardiac intervention, including cardiac transplantation.

Secondary end points were the (1) duration of mechanical ventilation $\geq 48$ hours postoperatively, (2) ICU length of stay, (3) hospital length of stay, and (4) development of low cardiac output syndrome (LCOS) within 48 hours after surgery. The definition of LCOS was derived from criteria published by Hoffman and colleagues, ${ }^{12}$ which included a combination of changes in clinical signs and biochemical indicators. Criteria included tachycardia, oliguria, poor perfusion, cardiac arrest, or metabolic acidosis, and the need for interventions aimed at augmenting cardiac output, such as increased pharmacologic support relative to the baseline and cardiac pacing.

\section{Calculations}

Inotrope use was quantified by a score adapted from Wernovsky and colleagues. ${ }^{13}$ The score was calculated from the level of inotropic support the patients were receiving (in micrograms/kilogram/ minute) at each sampling point according to the following equation: dopamine + dobutamine $+[$ (epinephrine + norepinephrine $) \times$ $100]+($ milrinone $\times 20)$.

\section{Data Analysis}

Differences in the continuous variables between groups were tested with the Student $t$ test or Mann-Whitney $U$ test. Differences in the categoric variables between groups were tested with the Fisher exact test. Correlations between variables were performed by the Spearman rank correlation method. The utility of BNP as a prognostic indicator of postoperative outcome was evaluated using receiver operating characteristic curves. Changes in BNP levels over time were compared by repeated-measures analysis of variance. Statistical analyses were performed with Prism 4.0 (GraphPad Software, Inc, San Diego, Calif) and Stata 9.0 (Stata Corp, College Station, Tex). 


\section{Results}

\section{Subjects}

Thirty-six consecutive patients were enrolled in the study. Twenty-five patients underwent BCPA, and 11 patients underwent TCPC. Of the 25 patients in the BCPA group, 1 patient underwent a hemi-Fontan procedure, 2 patients had bilateral superior venae cavae (SVC) with bilateral BCPA, and the remainder underwent BCPA of a single SVC. All 11 patients in the TCPC group had an extracardiac conduit placed between the inferior vena cava and the pulmonary artery, 4 of which were fenestrated.

All patients had a cardiac catheterization performed within 2 months before surgery. $\mathrm{CPB}$ was used in 32 patients (89\%). One patient could not be separated from CPB after TCPC until the TCPC was taken down. Only the preoperative BNP value was included in the analysis for this patient.

The patients' preoperative characteristics are shown in Table 1. The younger patients undergoing BCPA had faster heart rates, lower mean arterial pressure, higher mPAP, and larger Qp/Qs ratios than those undergoing TCPC.

\section{Outcomes}

Primary end points. Seven patients (19\%) had an adverse outcome, 5 of 25 patients in the BCPA group and 2 of 11 patients in the TCPC group. The preoperative diagnoses and specific postoperative events classifying the adverse outcomes are shown in Table 2. No enrolled patient died during the study period.

The demographic characteristics; degree of atrioventricular valve regurgitation; pre- and postoperative hemodynamic indices; and postoperative creatinine, lactate, and inotrope scores did not differ between patients undergoing BCPA with and without an adverse outcome. Additional surgery at the time of BCPA was required in 14 patients, including pulmonary artery plasty, aortoplasty, atrial reduction, and atrioventricular valve repair. The percentage of patients requiring additional surgery did not differ between patients with and without adverse postoperative outcome $(55 \%$ vs $60 \%)$.

Preoperative hemodynamics fulfilled institutional criteria for all patients undergoing a TCPC, including the 2 patients with an adverse outcome. Of these 2 patients, 1 had Ebstein's anomaly with a hypoplastic right ventricle and total anomalous pulmonary venous return that had been previously corrected at the time of BCPA. This patient also underwent atrial reduction at the time of TCPC. The second patient had an unbalanced atrioventricular septal defect with right atrial isomerism and anomalous right and middle hepatic veins. This patient underwent unifocalization of the right and middle hepatic veins at the time of TCPC. No patient with a good outcome after TCPC required additional surgery.

Circulatory arrest was used during the operation for 2 patients undergoing BCPA, neither of whom had an adverse
TABLE 1. Preoperative characteristics

\begin{tabular}{|c|c|c|c|}
\hline & ВCРA & TCPC & $P$ \\
\hline Patient No. & 25 & 11 & \\
\hline Age, mo & $7.6 \pm 9.3$ & $76.9 \pm 43.2$ & \\
\hline Weight, kg & $6.4 \pm 2.3$ & $20.3 \pm 11.4$ & \\
\hline Male, n (\%) & $17(68 \%)$ & $8(73 \%)$ & 1.0 \\
\hline \multirow{3}{*}{$\begin{array}{l}\text { Type of cardiac } \\
\text { lesion }\end{array}$} & 8 HLHS & 4 HLHS & \\
\hline & $\begin{array}{c}6 \text { DORV } \\
2 \text { Tricuspid } \\
\text { atresia }\end{array}$ & $\begin{array}{l}3 \text { DORV } \\
2 \text { DILV }\end{array}$ & \\
\hline & 2 PA-IVS & $\begin{array}{l}1 \text { Ebstein's } \\
\text { anomaly. HRV }\end{array}$ & \\
\hline \multirow[t]{2}{*}{$\begin{array}{l}3 \text { Unbalanced } \\
\text { AVSD }\end{array}$} & $1 \mathrm{TGA}, \mathrm{VSD}, \mathrm{HRV}$ & $\begin{array}{c}1 \text { Unbalanced } \\
\text { AVSD }\end{array}$ & \\
\hline & $\begin{array}{c}1 \text { TGA, VSD, PS, } \\
1 \text { DILV } \\
1 \text { Ebstein's } \\
\text { anomaly, HRV }\end{array}$ & & \\
\hline Heart rate, $\min ^{-1}$ & $129 \pm 18$ & $92 \pm 11$ & $<.0001$ \\
\hline $\begin{array}{l}\text { Mean arterial } \\
\text { pressure, } \mathrm{mm} \mathrm{Hg}\end{array}$ & $64 \pm 12$ & $75 \pm 15$ & .04 \\
\hline $\begin{array}{l}\text { Arterial oxygen } \\
\text { saturation, } \%\end{array}$ & $81 \pm 8$ & $83 \pm 5$ & .36 \\
\hline Op/Os & $1.6 \pm 0.7$ & $0.8 \pm 0.3$ & .001 \\
\hline PVR (Wood's unit) & $2.5 \pm 1.2$ & $1.9 \pm 0.9$ & .12 \\
\hline $\begin{array}{l}\text { Mean PA pressure, } \\
\text { mm Hg }\end{array}$ & $16 \pm 4$ & $11 \pm 4$ & .003 \\
\hline $\mathrm{Cl}, \mathrm{L} / \mathrm{min} / \mathrm{m}^{2}$ & $2.9 \pm 0.7$ & $3.4 \pm 1.6$ & .20 \\
\hline SVEDP, mm Hg & $9 \pm 3$ & $9 \pm 4$ & .80 \\
\hline
\end{tabular}

$B C P A$, Bidirectional cavopulmonary anastomosis; TCPC, total cavopulmonary connection; $Q p / Q s$ : ratio of pulmonary blood flow over systemic blood flow; $P V R$, pulmonary vascular resistance; $P A$, pulmonary artery; $\mathrm{Cl}$, cardiac index; SVEDP, systemic ventricular end-diastolic pressure; HLHS, hypoplastic left heart syndrome; $D O R V$, double outlet right ventricle; DILV, double inlet left ventricle; $P A-I V S$, pulmonary atresia-intact ventricular septum; TGA, transposition of great arteries; VSD, ventricular septal defect; HRV, hypoplastic right ventricle; $P S$, pulmonary stenosis; $A V S D$, atrioventricular septal defect. Data are presented as mean \pm standard deviation.

postoperative outcome. No patient in the TCPC group underwent circulatory arrest.

Secondary end points. Eight patients (22\%) required mechanical ventilation $\geq 48$ hours postoperatively, 7 of 25 patients in the BCPA group and 1 of 11 patients in TCPC group. The median duration of mechanical ventilation was 22 hours (range: 8-373 hours) in patients who underwent BCPA and 14 hours (range: 8-168 hours) in patients who underwent TCPC. Seven patients (19\%) developed LCOS within the first 48 hours after surgery, 4 of 25 patients in the BCPA group and 3 of 11 patients in TCPC group. The ICU stay and hospital stay were $6 \pm 5$ days and $13 \pm 9$ days in the BCPA group, respectively, and $6 \pm 2$ days and $18 \pm 10$ days in the TCPC group, respectively. 
TABLE 2. Diagnoses and specific postoperative events of patients with an adverse outcome

\begin{tabular}{|c|c|c|c|}
\hline Patient & Surgery & Diagnosis & Outcome \\
\hline 1 & BCPA & d-TGA, VSD, HRV & Reoperation for baffle leak and stenosis of the SVC-RPA junction at POD 3 \\
\hline 2 & BCPA & DORV & $\begin{array}{l}\text { Transcatheter stent dilatation of residual LPA stenosis because of high SVC pressure at } \\
\text { POD } 7\end{array}$ \\
\hline 3 & BCPA & HLHS & Transcatheter balloon dilatation for residual aortic arch stenosis at POD 7 \\
\hline 4 & BCPA & DORV & $\begin{array}{l}\text { Transcatheter device closure of the pulmonary valve because of SVC and PA } \\
\text { hypertension secondary to pulsatile forward flow and device closure of a large } \\
\text { decompressing hemiazygous vein at POD } 13\end{array}$ \\
\hline 5 & BCPA & HLHS & $\begin{array}{l}\text { Transferred for cardiac transplant because of persistently poor RV function, decision } \\
\text { made at POD } 12\end{array}$ \\
\hline 6 & TCPC & Ebstein's anomaly, HRV & $\begin{array}{l}\text { Fontan circulation taken down in the OR because of failed Fontan circulation, unable to } \\
\text { separate from CPB; another MBTS was added in the same operation. }\end{array}$ \\
\hline 7 & TCPC & Unbalanced AVSD & $\begin{array}{l}\text { Fontan circulation taken down } 11 \text { mo after operation because of PLE; also had ECLS } \\
\text { because of profound LCOS at PODs } 2-5\end{array}$ \\
\hline
\end{tabular}

$B C P A$, Bidirectional cavopulmonary anastomosis; TCPC, total cavopulmonary connection; $P O D$, postoperative day; $d$-TGA, dextraposed transposition of great arteries; VSD, ventricular septal defect; $H R V$, hypoplastic right ventricle; DORV, double outlet right ventricle; $H L H S$, hypoplastic left heart syndrome; $H R V$, hypoplastic right ventricle; $A V S D$, atrioventricular septal defect; $S V C$, superior vena cava; $R P A$, right pulmonary artery; $L P A$, left pulmonary artery; $R V$, right ventricle; $O R$, operating room; $C P B$, cardiopulmonary bypass; $P L E$, protein-losing enteropathy; MBTS, modified Blalock-Taussig shunt; ECLS, extracorporeal life support; $L C O S$, low cardiac output syndrome.

\section{Perioperative BNP Levels}

Perioperative BNP levels are shown in Table 3. BNP levels increased after surgery in all patients, with peak levels at 12 hours in 23 patients $(66 \%)$ and at 24 hours in 8 patients (23\%). BNP levels were greater preoperatively and at 2 and 12 hours postoperatively in the BCPA group than in the TCPC group (Table 3).

\section{Preoperative BNP Levels and Outcome}

BCPA group. Preoperative BNP levels were not different between patients with or without an adverse outcome, mechanical ventilation $\geq 48$ hours, or LCOS, and there was no correlation between preoperative BNP levels and ICU or hospital stay.

Preoperative BNP levels correlated with 2-hour BNP levels (rho $=0.84, P<.001$ ), but not with 12 - and 24hour BNP levels. There was no association between preoperative BNP levels and sex, and preoperative BNP levels did not correlate with preoperative weight, Qp/Qs, PVR, mPAP, cardiac index, SVEDP, mean arterial pressure, heart rate, arterial hemoglobin oxygen saturation, hematocrit, serum lactate, blood urea nitrogen, or creatinine.

TCPC group. Preoperative BNP levels were greater in patients with an adverse outcome than in patients with a good outcome (Figure 1). Preoperative BNP levels were not different between patients with or without mechanical ventilation $\geq 48$ hours, or LCOS, and there was no correlation between preoperative BNP levels and ICU or hospital stay.

Preoperative BNP levels correlated with 2-hour BNP levels (rho $=0.74, P=.03$ ), but not with 12 and 24-hour BNP levels. There was no association between preoperative BNP levels and sex, and preoperative BNP levels did not correlate with preoperative weight, Qp/Qs, PVR, mPAP, cardiac index, SVEDP, mean arterial pressure, heart rate, arterial oxygen saturation, hematocrit, serum lactate, urea, or creatinine.

\section{Postoperative BNP Levels and Outcome}

BCPA group. BNP levels at 12 and 24 hours were greater in patients with an adverse outcome than in patients with a good outcome (Figure 2). BNP levels at all postoperative time points were greater in patients requiring mechanical ventilation $\geq 48$ hours $(\mathrm{n}=7)$ than in patients requiring mechanical ventilation $<48$ hours $(\mathrm{n}=18, P<.05)$. In addition, BNP levels at 2, 12, and 24 hours correlated with the duration of mechanical ventilation (rho $=0.44, P=.02$; rho $=0.41, P=.04$; rho $=0.45, P=.02$, respectively). BNP levels at 12 hours were greater in patients who developed LCOS within 48 hours after surgery than in patients who did not $(913 \pm 693 \mathrm{pg} / \mathrm{mL}$ vs $308 \pm 299 \mathrm{pg} / \mathrm{mL}, P=$ .04). BNP levels at 2 hours correlated with ICU stay (rho $=0.47, P=.01$ ), and BNP levels at 2, 12, and 24 hours

TABLE 3. Perioperative B-type natriuretic peptide levels

\begin{tabular}{cccccc}
\hline Group & Pre BNP $(\mathrm{pg} / \mathrm{mL})$ & 2-h BNP $(\mathrm{pg} / \mathrm{mL})$ & 12-h BNP $(\mathrm{pg} / \mathrm{mL})$ & 24-h BNP (pg/mL) & ANOVA P \\
\hline BCPA $(\mathrm{n}=25)$ & $105 \pm 119^{*}(7-504)$ & $118 \pm 137^{*}(9-483)$ & $405 \pm 431^{* *}(49-1860)$ & $243 \pm 251(37-1140)$ & $<.0001$ \\
TCPC $\dagger(\mathrm{n}=11)$ & $28 \pm 33(5-121)$ & $26 \pm 21(8-79)$ & $117 \pm 89(38-334)$ & $121 \pm 113(22-403)$ & .001 \\
\hline
\end{tabular}

$B N P$, B-type natriuretic peptide; $A N O V A$, analysis of variance; $\mathrm{BCPA}$, bidirectional cavopulmonary anastomosis; $T C P C$, total cavopulmonary connection. Data are presented as mean \pm standard deviation (range). ${ }^{*} P<.05 .{ }^{*} P<.01$ vs TCPC group. $\dagger \mathrm{n}=10$ at 2,12 , and 24 hours. 


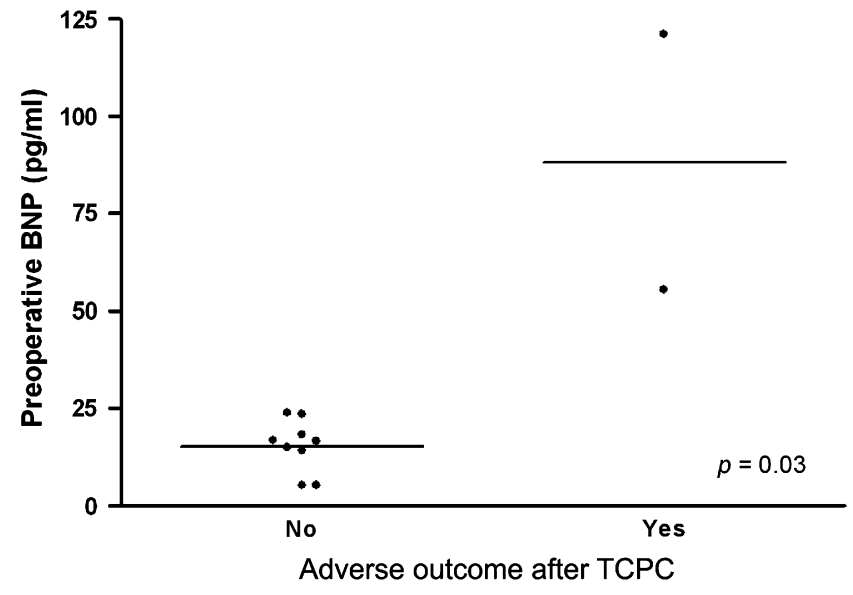

Figure 1. Comparisons of preoperative BNP levels between patients with $(n=2)$ and without $(n=9)$ adverse outcome after TCPC. Horizontal lines = mean values. BNP, B-type natriuretic peptide; TCPC, total cavopulmonary connection.

correlated with hospital stay $($ rho $=0.56, P=.003$; rho $=$ $0.40, P=.04$; rho $=0.39, P=.04$, respectively).

There were no correlations between postoperative BNP levels and mean arterial pressure, common atrial pressure, arterial oxygen saturation, hematocrit, urea, creatinine, or duration of CPB.

Receiver operating characteristic curves were used to evaluate various cutoff values of 12-hour BNP to predict an adverse outcome and mechanical ventilation $\geq 48$ hours. A 12-hour BNP cutoff value of $\geq 500 \mathrm{pg} / \mathrm{mL}$ had a sensitivity of $80 \%$ and a specificity of $80 \%$ for predicting an adverse outcome (area under the curve: 0.81, $P=.03$ ). A 12-hour BNP cutoff value of $\geq 500 \mathrm{pg} / \mathrm{mL}$ had a sensitivity of $86 \%$ and a specificity of $89 \%$ for predicting mechanical ventilation $\geq 48$ hours (area under the curve: $0.82, P=.01$ ).

Because a 12-hour BNP level $\geq 500 \mathrm{pg} / \mathrm{mL}$ predicted both an adverse outcome and mechanical ventilation $\geq 48$ hours, we dichotomized patients by BNP levels of $<500$ $\mathrm{pg} / \mathrm{mL}$ or $\geq 500 \mathrm{pg} / \mathrm{mL}$. The characteristics of patients with a 12-hour BNP level $<500 \mathrm{pg} / \mathrm{mL}$ and $\geq 500 \mathrm{pg} / \mathrm{mL}$ are shown in Table 4. Patients with a 12-hour BNP level $\geq$ $500 \mathrm{pg} / \mathrm{mL}$ had a greater incidence of LCOS and a longer ICU and hospital stay than patients with a 12-hour BNP level $<500 \mathrm{pg} / \mathrm{mL}$ (Table 4).

TCPC group. Postoperative BNP levels were not different between patients with or without an adverse outcome, mechanical ventilation $\geq 48$ hours, or LCOS, and there was no correlation between postoperative BNP levels and length of ICU or hospital stay.

\section{Other Variables and Outcome}

Age and preoperative hemodynamic data obtained from cardiac catheterizations were not associated with any primary or

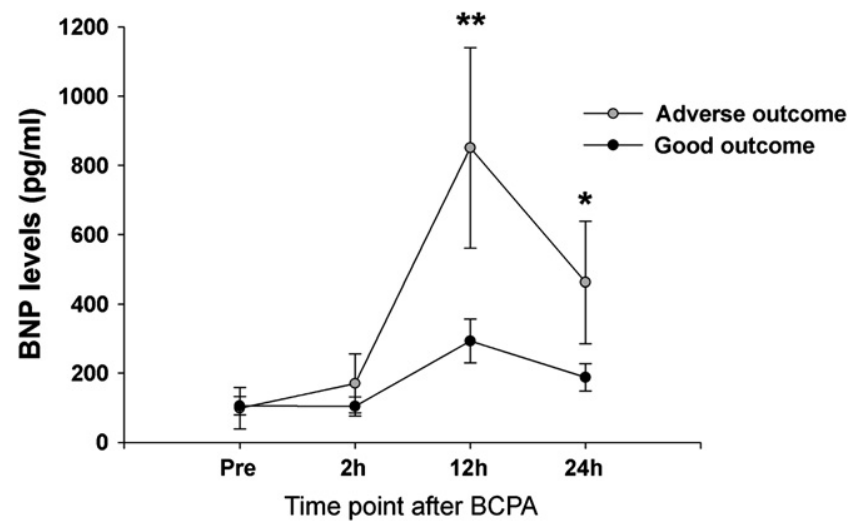

Figure 2. Comparison of perioperative BNP levels between patients with adverse or good outcome after BCPA. BNP levels at 12 and 24 hours are greater in patients with adverse outcome $(n=5)$ than in patients with good outcome $(n=20)$. There was a significant interaction between outcome and sample time $(P<.01)$. Data are presented as mean \pm standard error. $\left(^{*} P<.05\right.$ and ${ }^{*} P<.01$ vs good outcome.) $B N P$, B-type natriuretic peptide; $B C P A$, bidirectional cavopulmonary anastomosis.

secondary outcomes. We examined further the relationship between serum lactate and outcome. We found that 24-hour lactate levels were correlated with the duration of mechanical ventilation (rho $=0.52, P=.01$ ). In addition, 24-hour lactate levels were greater in patients who required mechanical ventilation $\geq 48$ hours than in patients who did not $(1.3 \pm 0.4$ $\mathrm{mmol} / \mathrm{L}$ vs $0.8 \pm 0.2 \mathrm{mmol} / \mathrm{L} ; P=.01)$. However, the mean lactate values in both groups were within the normal range for our laboratory.

\section{Discussion}

These data indicate that BNP levels predict outcome after BCPA and suggest a potential prognostic role for BNP before TCPC. Although lactate levels at 24 hours were correlated with the duration of mechanical ventilation, no other hemodynamic or biochemical data were associated with postoperative outcome. Previously identified risk factors for patients undergoing BCPA include atrioventricular valve regurgitation, elevated pulmonary artery pressure, a systemic right ventricle, anomalous pulmonary venous drainage, tricuspid valvuloplasty, elevated SVEDP, bilateral SVC, unbalanced atrioventricular septal defect, and heterotaxy syndrome. ${ }^{1,3,14}$ Although the present study was not designed primarily to evaluate individual risk factors for outcome after BCPA, we did not find an association between these factors and outcome, making BNP levels uniquely predictive of outcome after BCPA in this study.

Of the 11 patients undergoing TCPC in our study, 2 patients required takedown to a BCPA. Preoperative BNP levels were greatest in these patients. General criteria of 
TABLE 4. Characteristics of patients undergoing bidirectional cavopulmonary anastomosis with a 12-hour B-type natriuretic peptide level $<$ or $\geq 500 \mathrm{pg} / \mathrm{mL}$

\begin{tabular}{|c|c|c|c|}
\hline & 12-h BNP level $<500 \mathrm{pg} / \mathrm{mL}$ & 12-h BNP level $\geq 500 \mathrm{pg} / \mathrm{mL}$ & $\boldsymbol{P}$ \\
\hline Patient No. $(\%)$ & $17(68 \%)$ & $8(32 \%)$ & \\
\hline Age, mo & $7.8 \pm 10.6$ & $7.2 \pm 6.1$ & .97 \\
\hline Weight, kg & $5.9 \pm 1.7$ & $6.4 \pm 2.5$ & .60 \\
\hline Male, n (\%) & $12(71 \%)$ & $5(62 \%)$ & 1.0 \\
\hline \multicolumn{4}{|l|}{ Preoperative hemodynamic data } \\
\hline Qp/0s & $1.7 \pm 0.8$ & $1.3 \pm 0.5$ & .22 \\
\hline PVR, Wood's unit & $2.5 \pm 1.4$ & $2.7 \pm 1.1$ & .74 \\
\hline Mean PA pressure, $\mathrm{mm} \mathrm{Hg}$ & $15 \pm 3$ & $17 \pm 5$ & .23 \\
\hline $\mathrm{Cl}, \mathrm{L} / \mathrm{min} / \mathrm{m}^{2}$ & $2.7 \pm 0.7$ & $3.4 \pm 0.8$ & .08 \\
\hline SVEDP, $\mathrm{mm} \mathrm{Hg}$ & $10 \pm 3$ & $8 \pm 2$ & .17 \\
\hline \multicolumn{4}{|l|}{ Postoperative data at $12 \mathrm{~h}$} \\
\hline Heart rate, $\min ^{-1}$ & $120 \pm 14$ & $127 \pm 16$ & .31 \\
\hline Mean arterial pressure, $\mathrm{mm} \mathrm{Hg}$ & $71 \pm 10$ & $70 \pm 10$ & .82 \\
\hline Common atrial pressure, $\mathrm{mm} \mathrm{Hg}$ & $7 \pm 3$ & $8 \pm 2$ & .91 \\
\hline Serum creatinine, $\mathrm{mg} / \mathrm{dL}$ & $0.4 \pm 0.1$ & $0.5 \pm 0.1$ & .11 \\
\hline Serum lactate, $\mathrm{mmol} / \mathrm{L}$ & $1.1 \pm 0.6$ & $1.2 \pm 0.5$ & .83 \\
\hline Inotrope score & $9 \pm 4.5$ & $12 \pm 6.5$ & .23 \\
\hline \multicolumn{4}{|l|}{ Outcomes } \\
\hline LCOS, n (\%) & $1(6 \%)$ & $3(38 \%)$ & .08 \\
\hline ICU length of stay, $d$ & $4 \pm 2$ & $11 \pm 7$ & .001 \\
\hline Hospital length of stay, $d$ & $9 \pm 5$ & $20 \pm 12$ & .003 \\
\hline Duration of mechanical ventilation, $\mathrm{h}$ & $20 \pm 9$ & $165 \pm 149$ & .004 \\
\hline Adverse outcome, $\mathrm{n}(\%)$ & $1(6 \%)$ & $4(50 \%)$ & .02 \\
\hline
\end{tabular}

$B N P$, B-type natriuretic peptide; $Q p / Q$ s: ratio of pulmonary blood flow over systemic blood flow; $P V R$, pulmonary vascular resistance; $P A$, pulmonary artery; $C l$, cardiac index; SVEDP, systemic ventricular end-diastolic pressure; $L C O S$, low cardiac output syndrome; ICU, intensive care unit. Data are presented as mean \pm standard deviation.

suitability for TCPC have been described and include normal systemic venous return, mPAP less than $15 \mathrm{~mm} \mathrm{Hg}$, low PVR, good ventricular function, a competent atrioventricular valve, and the absence of pulmonary artery distortion. ${ }^{5}$ With the exception of 1 patient with a good outcome who had a preoperative mPAP greater than $15 \mathrm{~mm} \mathrm{Hg}$ (but also an elevated left atrial pressure and a normal calculated PVR), all of the patients met these criteria. These findings suggest that preoperative BNP levels may provide valuable supplemental data to aid in decisions regarding the timing or advisability of a TCPC.

We found that BNP levels increased after BCPA and TCPC. This finding is in contrast with a study by Sun and colleagues ${ }^{15}$ that found no change in BNP levels after BCPA or Fontan. Because preoperative, but not postoperative, BNP levels were greater in their cohort than ours, the inconsistency between groups may be explained by differences in preoperative hemodynamics. In a study of 9 patients that included 4 patients after TCPC, Ationu and colleagues ${ }^{16}$ reported decreases in BNP after surgery. However, in a larger study of 30 patients after TCPC, Yoshimura and colleagues ${ }^{17}$ found that BNP levels increased postoperatively in a manner similar to patients in our study. Furthermore, in a study of 25 patients that included 5 patients with BCPA and 5 patients with TCPC, Costello and colleagues ${ }^{18}$ found that BNP levels increased after surgery in both groups and correlated with CPB time. A relationship between perioperative BNP levels and outcome was not found in any of these prior studies, and thus the present study is the first to suggest a prognostic role for BNP in this patient population.

The regulation of BNP production and release in health and disease remains incompletely understood. However, in vivo and in vitro investigations demonstrate that ventricular volume and pressure loading increase BNP expression. ${ }^{19-21}$ In addition, several stimuli relevant to patients undergoing cardiac surgery, including catecholamines, endothelin-1, and cytokines, have been demonstrated to increase BNP expression. ${ }^{21,22}$ Last, several additional factors with particular importance for patients with single ventricle physiology have been correlated with BNP levels, including hypoxia and the Qp/Qs ratio. ${ }^{23,24}$ In the present study, preoperative BNP levels were greater in patients before BCPA than TCPC. This result is consistent with several previous studies, but not all. ${ }^{18,25-28}$ However, our findings are in keeping with increased volume and pressure loading after stage 1 palliation, reflected by higher mPAP and larger Qp/Qs ratios in patients before BCPA compared with patients before TCPC. 
The mechanisms underlying the greater increase in BNP in patients with an adverse outcome are likely variable, but speculative. Three patients with an adverse outcome had residual defects that resulted in increased SVC pressure and decreased pulmonary blood flow. A recent study by Law and colleagues $^{25}$ of patients with cavopulmonary connections found that BNP levels increased with ventricular failure but not with isolated cavopulmonary failure, defined as systemic venous congestion without evidence of ventricular dysfunction. The study of Law and colleagues included mostly an outpatient population, whereas the present study focused on the immediate perioperative period. In addition, because patients with an adverse outcome in our study also had an increased incidence of LCOS, it is possible that the patients with residual anatomic defects of the cavopulmonary circuit also had ventricular dysfunction or an elevated afterload. One patient with an adverse outcome in the BCPA group required transcatheter aortic dilation for residual aortic arch obstruction. The elevation in BNP in this patient is consistent with previous reports after relief of left ventricular outflow tract obstruction. ${ }^{29}$ Finally, the mechanisms responsible for an elevation in preoperative BNP in patients with an adverse outcome after TCPC are unclear, particularly given that the preoperative hemodynamics were not different from patients with good outcome. We speculate that because BNP is a cardiac hormone, it may reflect myocardial dynamics in a unique manner that is more sensitive than current diagnostic methods.

We chose the duration of mechanical ventilation as a secondary end point because it is a common surrogate marker of disease severity that has been correlated to BNP levels in previous studies of patients after congenital cardiac surgery. ${ }^{8-10}$ Given the potential deleterious effects of positive pressure ventilation and salutary effects of spontaneous respiration for patients with superior or complete cavopulmonary connections, our institutional practice is to separate patients from mechanical ventilation as early in their postoperative course as possible. Indeed, mechanical ventilation beyond 48 hours, the specific end point used in our study, is unusual, and thus represents an unexpected clinical outcome. It must be noted that there are no validated criteria for the discontinuation of mechanical ventilation for patients after BCPA or TCPC, and thus the decision to separate a patient from the ventilator was made on an individual basis by the attending physicians, who were blinded to the BNP values.

In addition, we used the development of LCOS as a secondary outcome, because it has been used as an end point in therapeutic trials in pediatric patients after cardiac surgery. ${ }^{12}$ However, the majority of patients with LCOS developed it early in the postoperative course, before the 12-hour time point. Thus, postoperative BNP levels did not predict LCOS, but rather were associated with it. Whether therapies initiated in response to elevated BNP levels in the postoperative period could decrease the incidence of LCOS was not evaluated, but this warrants further study.
A limitation of this study is the sample size. Only 2 patients had a poor outcome after TCPC. However, because BNP was the only predictor of outcome, we suggest that it was an important finding and at least warrants a larger prospective study that would permit multivariate analysis.

\section{Conclusions}

We found that postoperative BNP levels predict important outcomes after BCPA and that a cutoff of $500 \mathrm{pg} / \mathrm{mL} 12$ hours after surgery was a sensitive and specific predictor of an unplanned cardiac intervention and mechanical ventilation beyond 48 hours. In addition, we found that preoperative BNP levels were greater in patients with early or late takedown of the TCPC than in those with a successful operation. Additional studies are warranted to define further the role of BNP in the management of these patients, but our study suggests that elevated BNP levels after BCPA should prompt a careful evaluation of hemodynamics and ventricular function, an investigation of the surgical accuracy of the anastomosis, and a search for additional anatomic defects. We suggest that BNP levels may be useful in the preoperative evaluation of patients considered for a TCPC.

The authors thank nurse practitioners Megan Tracey, Julie Bushnell, and Laura Presnell, the pediatric critical care fellows, the cardiac intensive care nurses, the Pediatric Clinical Research Center, Adam Gorham, and Leslie Kurkjian for their invaluable assistance with the study.

\section{References}

1. Scheurer MA, Hill EG, Vasuki N, Maurer S, Graham EM, Bandisode V, et al. Survival after bidirectional cavopulmonary anastomosis: analysis of preoperative risk factors. J Thorac Cardiovasc Surg. 2007;134: 82-9. 89.e1-2.

2. Mahle WT, Cohen MS, Spray TL, Rychik J. Atrioventricular valve regurgitation in patients with single ventricle: impact of the bidirectional cavopulmonary anastomosis. Ann Thorac Surg. 2001;72:831-5.

3. Alejos JC, Williams RG, Jarmakani JM, Galindo AJ, Isabel-Jones JB, Drinkwater D, et al. Factors influencing survival in patients undergoing the bidirectional Glenn anastomosis. Am J Cardiol. 1995;75:1048-50.

4. Gentles TL, Mayer JE Jr, Gauvreau K, Newburger JW, Lock JE, Kupferschmid JP, et al. Fontan operation in five hundred consecutive patients: factors influencing early and late outcome. J Thorac Cardiovasc Surg. 1997;114:376-91.

5. Hosein RB, Clarke AJ, McGuirk SP, Griselli M, Stumper O, De Giovanni JV, et al. Factors influencing early and late outcome following the Fontan procedure in the current era. The 'Two Commandments'? Eur J Cardiothorac Surg. 2007;31:344-53.

6. Sudoh T, Kangawa K, Minamino N, Matsuo H. A new natriuretic peptide in porcine brain. Nature. 1988;332:78-81.

7. Levin ER, Gardner DG, Samson WK. Natriuretic peptides. N Engl J Med. 1998;339:321-8.

8. Hsu J, Keller R, Chikovani O, Cheng H, Hollander S, Karl T, et al. B-type natriuretic peptide levels predict outcome after neonatal cardiac surgery. J Thorac Cardiovasc Surg. 2007;134:939-45.

9. Cannesson M, Bionda C, Gostoli B, Raisky O, di Filippo S, Bompard D, et al. Time course and prognostic value of plasma B-type natriuretic peptide concentration in neonates undergoing the arterial switch operation. Anesth Analg. 2007;104:1059-65, tables of contents.

10. Shih CY, Sapru A, Oishi P, Azakie A, Karl TR, Harmon C, et al. Alterations in plasma B-type natriuretic peptide levels after repair of 
congenital heart defects: a potential perioperative marker. J Thorac Cardiovasc Surg. 2006;131:632-8.

11. Chikovani O, Hsu J, Keller R, Karl T, Azakie A, Adatia I, et al. B-type natriuretic peptide levels predict outcomes for children on extracorporeal life support after cardiac surgery. J Thorac Cardiovasc Surg. 2007;134: 1179-87.

12. Hoffman TM, Wernovsky G, Atz AM, Kulik TJ, Nelson DP, Chang AC, et al. Efficacy and safety of milrinone in preventing low cardiac output syndrome in infants and children after corrective surgery for congenital heart disease. Circulation. 2003;107:996-1002.

13. Wernovsky G, Wypij D, Jonas RA, Mayer JE Jr, Hanley FL, Hickey PR, et al. Postoperative course and hemodynamic profile after the arterial switch operation in neonates and infants. A comparison of low-flow cardiopulmonary bypass and circulatory arrest. Circulation. 1995;92: 2226-35.

14. Day RW, Orsmond GS, Sturtevant JE, Hawkins JA, Doty DB, McGough EC. Early and intermediate results of the Fontan procedure at moderately high altitude. Ann Thorac Surg. 1994;57:170-6.

15. Sun LS, Dominguez C, Mallavaram NA, Quaegebeur JM. Dysfunction of atrial and B-type natriuretic peptides in congenital univentricular defects. J Thorac Cardiovasc Surg. 2005;129:1104-10.

16. Ationu A, Singer DR, Smith A, Elliott M, Burch M, Carter ND. Studies of cardiopulmonary bypass in children: implications for the regulation of brain natriuretic peptide. Cardiovasc Res. 1993;27:1538-41.

17. Yoshimura N, Yamaguchi M, Oshima Y, Oka S, Ootaki Y, Hasegawa T, et al. Suppression of the secretion of atrial and brain natriuretic peptide after total cavopulmonary connection. J Thorac Cardiovasc Surg. 2000; 120:764-9.

18. Costello JM, Backer CL, Checchia PA, Mavroudis C, Seipelt RG, Goodman DM. Effect of cardiopulmonary bypass and surgical intervention on the natriuretic hormone system in children. J Thorac Cardiovasc Surg. 2005;130:822-9.

19. Zhang Y, Carreras D, de Bold AJ. Discoordinate re-expression of cardiac fetal genes in N(omega)-nitro-L-arginine methyl ester (L-NAME) hypertension. Cardiovasc Res. 2003;57:158-67.
20. Schaub MC, Hefti MA, Harder BA, Eppenberger HM. Various hypertrophic stimuli induce distinct phenotypes in cardiomyocytes. $J$ Mol Med. 1997;75:901-20.

21. Hama N, Itoh H, Shirakami G, Nakagawa O, Suga S, Ogawa Y, et al. Rapid ventricular induction of brain natriuretic peptide gene expression in experimental acute myocardial infarction. Circulation. 1995;92:1558-64.

22. Ma KK, Ogawa T, de Bold AJ. Selective upregulation of cardiac brain natriuretic peptide at the transcriptional and translational levels by pro-inflammatory cytokines and by conditioned medium derived from mixed lymphocyte reactions via p38 MAP kinase. J Mol Cell Cardiol. 2004;36:505-13.

23. Hopkins WE, Chen Z, Fukagawa NK, Hall C, Knot HJ, LeWinter MM. Increased atrial and brain natriuretic peptides in adults with cyanotic congenital heart disease: enhanced understanding of the relationship between hypoxia and natriuretic peptide secretion. Circulation. 2004; 109:2872-7.

24. Suda K, Matsumura M, Matsumoto M. Clinical implication of plasma natriuretic peptides in children with ventricular septal defect. Pediatr Int. 2003;45:249-54.

25. Law YM, Ettedgui J, Beerman L, Maisel A, Tofovic S. Comparison of plasma B-type natriuretic peptide levels in single ventricle patients with systemic ventricle heart failure versus isolated cavopulmonary failure. Am J Cardiol. 2006;98:520-4.

26. Koch A, Zink S, Singer H. B-type natriuretic peptide in paediatric patients with congenital heart disease. Eur Heart J. 2006;27:861-6.

27. Hjortdal VE, Stenbog EV, Ravn HB, Emmertsen K, Jensen KT, Pedersen EB, et al. Neurohormonal activation late after cavopulmonary connection. Heart. 2000;83:439-43.

28. Wahlander H, Westerlind A, Lindstedt G, Lundberg PA, Holmgren D. Increased levels of brain and atrial natriuretic peptides after the first palliative operation, but not after a bidirectional glenn anastomosis, in children with functionally univentricular hearts. Cardiol Young. 2003; 13:268-74.

29. Cowley CG, Bradley JD, Shaddy RE. B-type natriuretic peptide levels in congenital heart disease. Pediatr Cardiol. 2004;25:336-40.

\section{The Journal of Thoracic and Cardiovascular Surgery Conflict of Interest Policy}

To assure fairness to authors submitting work for consideration in The Journal of Thoracic and Cardiovascular Surgery, a mechanism exists for managing conflicts of interest. The editor and each of the section editors complete a "Conflict of Interest" form that identifies any and all relationships with commercial and other academic entities. When the editor has a potential conflict because of a relationship with another entity or author, the editor appoints an alternate editor from among the section editors or editorial board members who assumes the entire responsibility for final decisions on the manuscript in question. The editor does not read the reviews that are submitted nor engage in discussing the manuscript prior to the final decision. When the conflict of interest involves a section editor, a "guest section editor" is appointed who fills the role normally played by the conflicted section editor. All members of the editorial board and reviewers are asked to indicate any conflict of interest when they agree to review a manuscript. 